\title{
Estimation of applied stress in the near threshold of fatigue crack propagation utilizing high frequency current impedance and hardness measurement
}

\author{
$\mathrm{Y}$ oshiyuki K ondo ${ }^{1}$, Takuya $\mathrm{O}$ gawa ${ }^{2}$ and $\mathrm{M}$ asanobu $\mathrm{K}$ ubota ${ }^{1}$ \\ 1. Department of Intelligent M achinery \& Systems, K yushu U niversity, Fukuoka, J apan \\ 2. G raduate School of K yushu University, Fukuoka, J apan
}

\begin{abstract}
In the failure analysis of fatigue fracture accident of industrial machinery, the estimation of applied stress on the fatigue crack is an important issue in order to determine the cause of failure and to prevent another accident. The estimation of applied stress using fractographic technique has been al ready established. However, the estimation can be applicable in relatively high stress intensity factor region. Low stress intensity factor region, however, is much more important in the real engineering. The objective of this study is the development of estimation method of applied stress, which can be used in the near threshold region of crack propagation. High frequency current impedance method and fracture surface hardness method were examined. In the impedance method, there was a correlation between the high frequency current impedance of fatigue fracture surface and stress intensity factor range. In the hardness method, micro Vickers hardness was measured on the fatigue fracture surface. The hardness parameter of fatigue fracture surface was defined as the area of indentation mark in order to reduce the effect of surface roughness of the fatigue fracture surface. The hardness parameter had a correlation with the stress intensity factor range in the near threshold region. Each method can be used in the stress estimation in low stress intensity factor region.
\end{abstract}

Key words: Fatigue, Applied stress estimation, Austenitic stainless steel, Failure analysis, High frequency current impedance, $\mathrm{H}$ ardness

\section{INTRODUCTION}

The estimation of actual stress applied to a machinery component is necessary when a failure accident occurs. It is essential to know the applied stress of the failure part for the failure analysis. It is also useful to prevent other accident. The actual loading conditions, which were applied to the fractured component, are not available in many cases. Therefore, fatigue fracture surface in which loading history must be left is critically important.

There is an established technique to estimate the applied stress from the fatigue fracture surface. The technique uses the striations observed on the fatigue fracture surface and the fact that the striation spacing corresponds to the crack propagation rate [1]. However, this technique is not fundamentally applicable for relatively low crack propagation rate region, which is important in the sense that it is near the crack initiation site, because striations could be produced in the limited range of crack propagation rate and stress intensity factor range. In austenitic stainless steel, striation can be usually observed in the region where the crack propagation rate is higher than $10^{-7} \mathrm{~m} /$ cycle.

The objective of this paper is to develop the estimation method of applied stress using fatigue fracture surface. The method should be applicable to relatively low da/dN or $\Delta \mathrm{K}$ condition where no striation is produced. In the previous studies, estimation method using surface roughness measured on the fatigue fracture surface was proposed [2]. A nother method using hardness distribution below the fatigue fracture surface was also examined.
However, both methods had some problems. The difficulty of the former method was that there was no unique relationship between the surface roughness and stress intensity factor range. The latter had a problem that hardness distribution depended not on stress intensity factor range but on the maximum stress intensity factor [3]. Furthermore, the latter method is a destructive method and needs to cut out the fatigue fracture surface. Therefore, this study aims to develop non-destructive methods.

In this study, two estimation methods were examined. One is based on the electrical impedance measured on the fatigue fracture surface using high-frequency current. A nother is based on the hardness measurement on the fatigue fracture surface.

\section{CONCEPTS OF ESTIMATION METHODS}

\subsection{High frequency current impedance method}

The basic idea of this method is that an electrical resistance of a fatigue fracture surface is supposed to be related with loading condition. A plastic zone is formed at the fatigue crack tip. The fatigue crack propagates across through it. As a result, thin plastic deformed layer is left on the fracture surface. Figure 1 shows a schematic illustration of the plastic deformation layer produced on the fatigue fracture surface. The amount of plastic strain and the size of plastic zone depend on stress intensity factor of the crack. On the other hand, electrical resistance of metal is supposed to change by plastic strain applied to the material due to the increase of dislocations, the de- 
velopment of slip band, deformation of crystal grain, etc. Consequently, if a relationship between the electrical resistance of fatigue fracture surface and the stress intensity factor applied to fatigue fracture surface is determined, the applied stress could be estimated by the measurement of electrical resistance of fracture surface.

\subsection{Hardness measurement method}

The hardness of fatigue fracture surface must be increased by plastic deformation and depends on stress intensity factor of the crack. Therefore, it is expected to be used for applied stress estimation.

\section{FATIGUE CRACK PROPAGATION TEST}

\subsection{Test material and test specimen}

Test materials are two kinds of austenitic stainless steels, which are SUS304 and SUS316L. The materials received solution heat treatment. The chemical composition of test materials is shown in Table 1. The mechanical properties of test materials are shown in Table 2.

Compact Tension (CT) specimen was used for the experiment. The configuration of CT specimen is shown in Fig. 2. The notch of CT specimen was introduced by electrical discharge method. Crack propagation test was done to prepare the fatigue fracture surface which had a given loading history. The specimen and test conditions were based on ASTM E647.

\subsection{Fatigue crack propagation test result}

Crack length was continuously measured using a back face strain gauge by the unloading elastic compliance method. Cyclic loading frequency was $28.4 \mathrm{~Hz}$.

There are two kinds of crack tip plastic zones depending on formation mechanism as shown in Fig. 3. One is formed by the monotonic load. Another is formed by the cyclic load. Decreasing stress intensity factor range tests

Table 1. Chemical compositions of test materials (wt.\%).

\begin{tabular}{|c|c|c|c|c|c|c|c|c|}
\hline Material & $\mathrm{C}$ & $\mathrm{Si}$ & $\mathrm{Mn}$ & $\mathrm{P}$ & $\mathrm{S}$ & $\mathrm{Ni}$ & $\mathrm{Cr}$ & $\mathrm{Mo}$ \\
\hline SUS304 & 0.04 & 0.49 & 1.01 & 0.028 & 0.002 & 8.27 & 18.24 & - \\
\hline SUS316L & 0.019 & 0.49 & 0.83 & 0.028 & 0.001 & 12.30 & 17.32 & 2.87 \\
\hline
\end{tabular}

Table 2. Mechanical properties of test materials.

\begin{tabular}{|c|c|c|c|c|}
\hline Material & $\begin{array}{c}\sigma_{0.2} \\
(\mathrm{MPa})\end{array}$ & $\begin{array}{c}\sigma_{\mathrm{B}} \\
(\mathrm{MPa})\end{array}$ & $\begin{array}{c}\delta \\
(\%)\end{array}$ & $\begin{array}{c}\phi \\
(\%)\end{array}$ \\
\hline SUS304 & 219 & 644 & 81.1 & 84.0 \\
\hline SUS316L & 217 & 615 & 68.7 & 79.8 \\
\hline
\end{tabular}

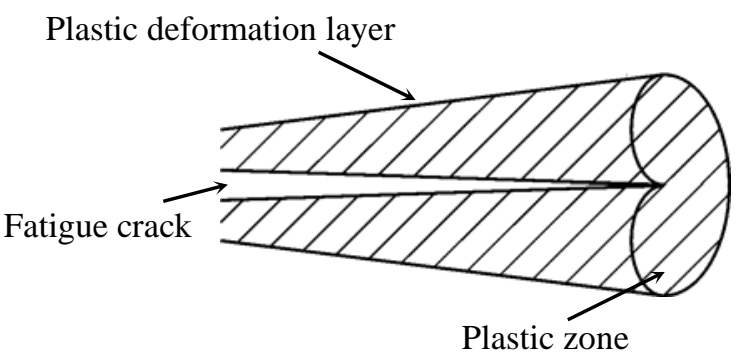

Fig. 1. Plastic zone at crack tip were done by using two kinds of loading conditions. One was a loading condition that the stress ratio $R$ was constant at 0.1 . Another was a loading condition that the maximum stress intensity factor was constant. The loading sequence of constant $K_{\max }$ test is shown in Fig. 4. The loading was controlled so that the maximum stress intensity factor was kept constant and stress intensity factor range was decreased with the increase of crack length.

Fatigue crack propagation tests were mainly done in near threshold region where striation could not be produced. The fatigue crack propagation behaviors are shown in Figs. 5 and 6.

\subsection{Fractographic study}

Photographs of the fatigue fracture surface of SUS304 and SUS316L for $R=0.1$ observed by SEM are shown in Figs. 7 and 8. Striations were observed in the photo (c) for both materials for relatively high stress intensity factor range. Striations were not observed in other photos for low stress intensity factor range.

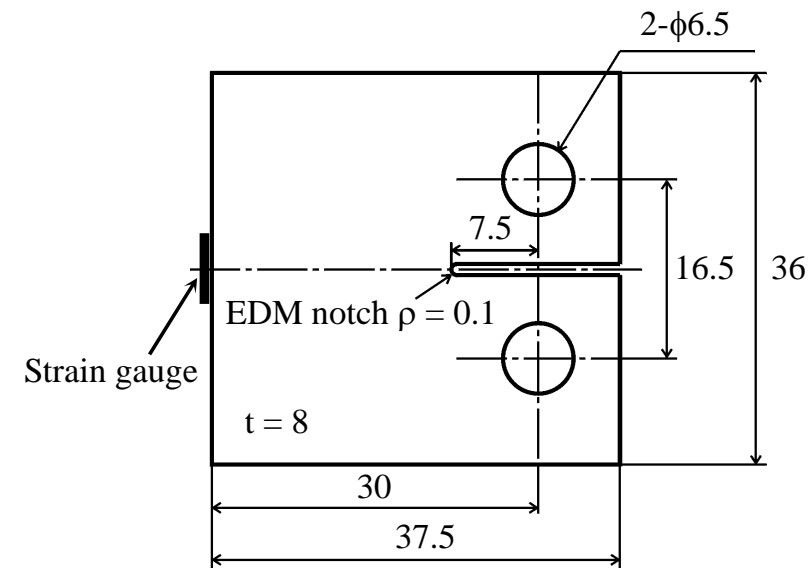

Fig. 2. CT specimen (dimensions are in $\mathrm{mm}$ ).

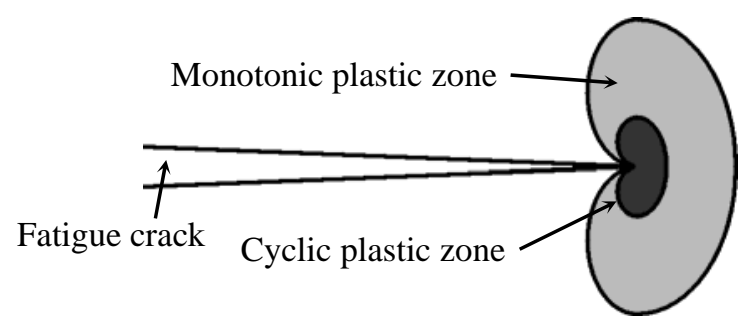

Fig. 3. Monotonic plastic zone and cyclic plastic zone

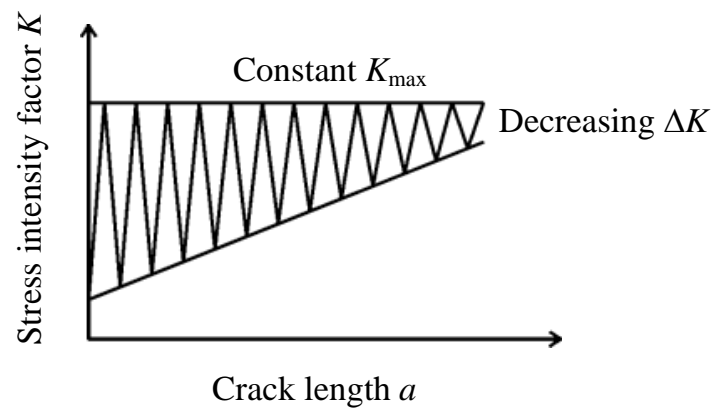

Fig. 4. Constant $K_{\max }$, decreasing $\Delta K$ test 


\section{HIGH FREQUENCY IMPEDANCE METHOD}

\subsection{Skin effect}

In this method, the electrical resistance of fatigue fracture surface was measured using high frequency current. High frequency current has a characteristic that the current flows near the surface as shown in Fig. 9. The depth of current is varied depending on the current frequency so that the higher frequency decreases the penetration depth of current flow below surface. The thickness of plastic deformation layer formed on fatigue fracture surface is less than several hundreds $\mu \mathrm{m}$. Therefore, utilization of high frequency current is very effective for the measurement of electrical resistance of fatigue fracture surface. Since high frequency current was used in this experiment, it would be better to describe as not resistance but impedance. The relationship between skin depth and current frequency is estimated as shown in Fig. 10 [4].

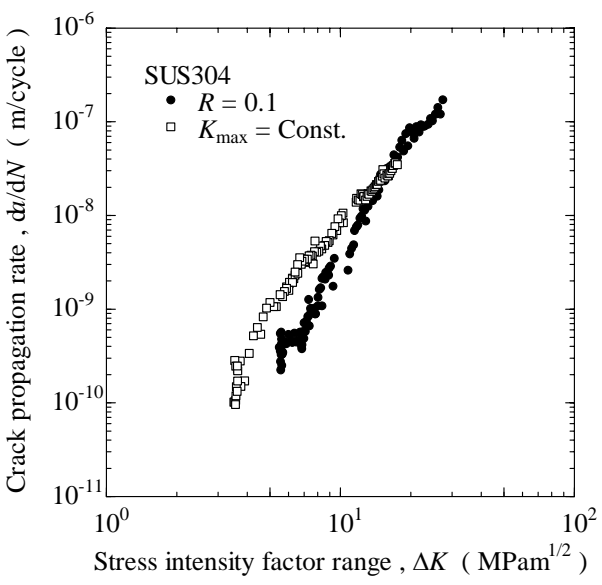

Fig. 5. Crack propagation behavior of SUS304

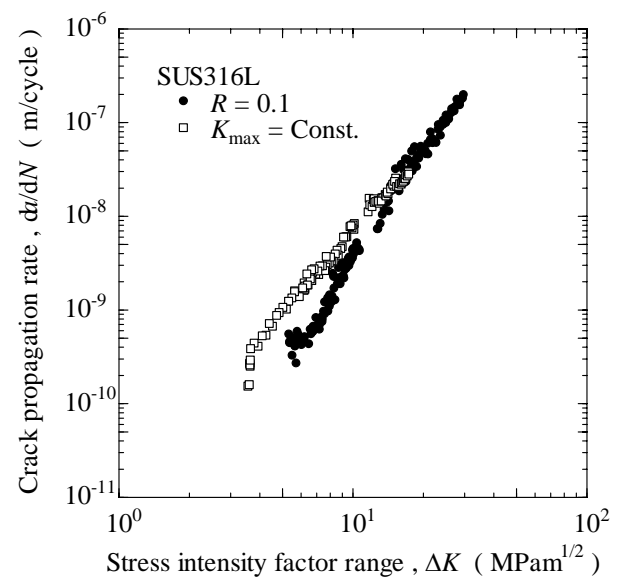

Fig. 6. Crack propagation behavior of SUS316L

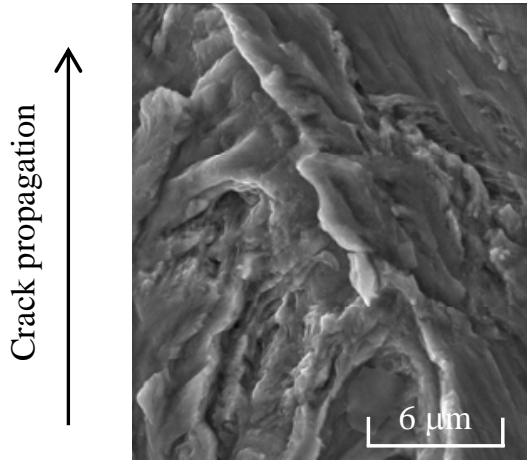

(a) $\Delta K=6.2 \mathrm{MPam}^{1 / 2}$

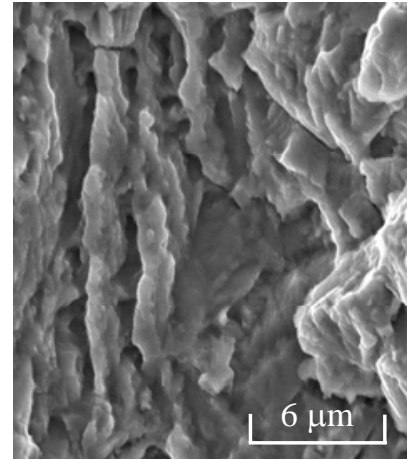

(b) $\Delta K=19.5 \mathrm{MPam}^{1 / 2}$

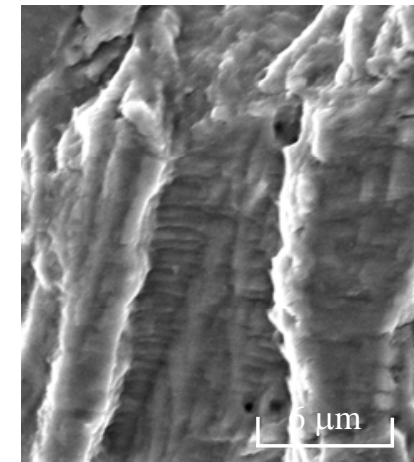

(c) $\Delta K=26.9 \mathrm{MPam}^{1 / 2}$

Fig. 7. Fatigue fracture surface of SUS304

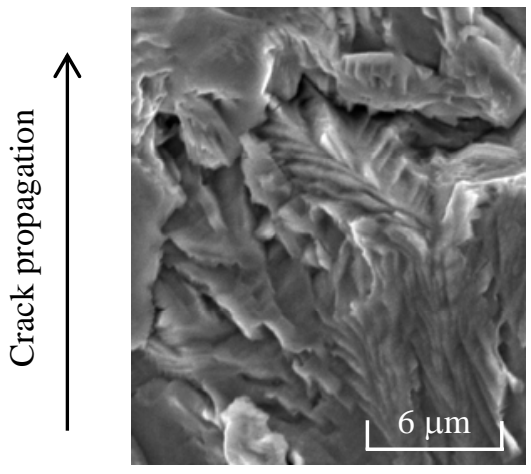

(a) $\Delta K=6.6 \mathrm{MPam}^{1 / 2}$



(b) $\Delta K=15.3 \mathrm{MPam}^{1 / 2}$

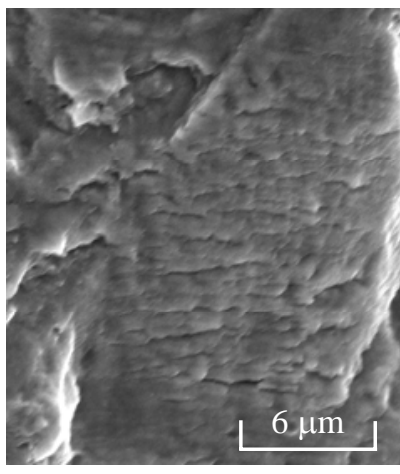

(c) $\Delta K=26.5 \mathrm{MPam}^{1 / 2}$

Fig. 8. Fatigue fracture surface of SUS316L 


\subsection{Experimental procedure}

\subsubsection{Measurement method}

An equipment for the measurement of electrical impedance of fatigue fracture surface is shown in Fig. 11. The equipment consists of a function generator, an oscilloscope, a differential amplifier, a shunt resistance and four probes. The potential drop caused by the shunt resistance and the fatigue fracture surface were measured by the oscilloscope. The potential drop caused by the fatigue fracture surface, which was very small quantity, was magnified using the differential amplifier by 200 times. The circuit current was calculated from the known shunt resistance and the potential drop caused by the shunt resistance. The electrical impedance of the fatigue fracture surface was calculated from the circuit current and the potential drop caused by the fatigue fracture surface.

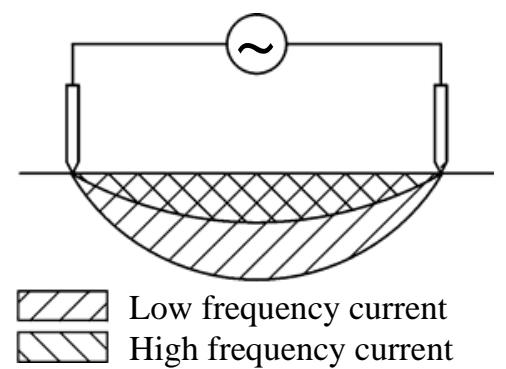

Fig. 9. Skin effect

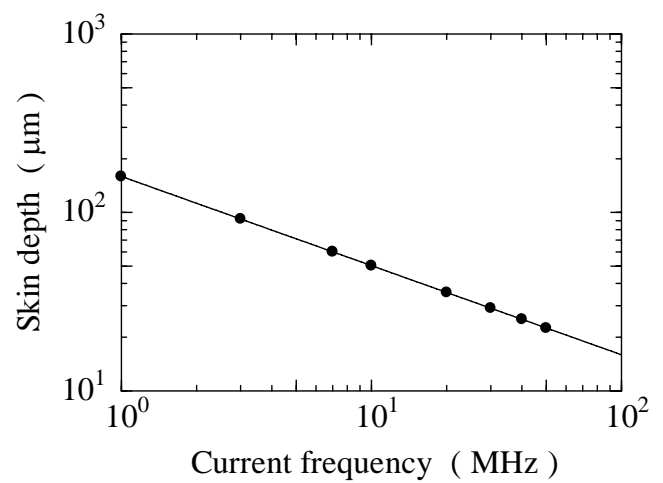

Fig. 10. Relation between the skin depth and the current frequency [4]

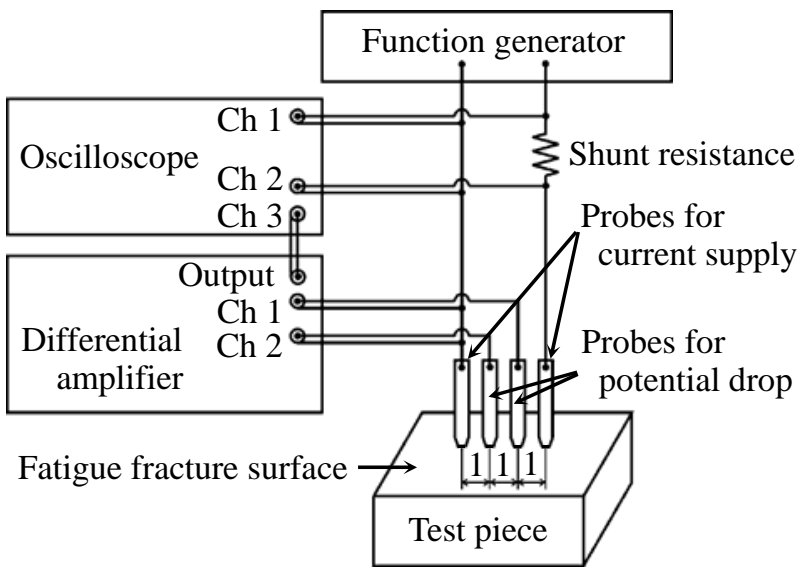

Fig. 11. Electrical impedance measurement method

\subsubsection{Resonance characteristic of the circuit}

Prior to the experiments of applied stress estimation, current frequency, voltage amplitude and shunt resistance were varied to determine appropriate measurement conditions. The results are shown in Fig. 12. The impedance of fatigue fracture surface had a peak at a certain frequency depending on shunt resistance due to the resonance properties of the circuit. The highest impedance was obtained by $47 \Omega$ of shunt resistance at $28 \mathrm{MHz}$. In this experiment, $47 \Omega$ of shunt resistance, $23 \mathrm{MHz}$ of high frequency current and $250 \mathrm{mV}$ of voltage amplitude were used. To avoid the instability of the measurement, the current frequency was slightly decreased from the actual resonance frequency. The maximum voltage amplitude was determined by the performance of differential amplifier.

\subsection{Results and discussions}

\subsubsection{Electrical impedance}

The results are shown in Fig. 13. The material is SUS304. There was a positive correlation between the electrical impedance and stress intensity factor range in each test piece. However, there was large difference among the results of test pieces. The difference was supposed to be caused by the environment in which measurements were done. Therefore, to reduce the difference depending on the test piece, the electrical impedance of the fatigue fracture surface $Z$ was normalized by that of unstrained material surface $Z_{0}$ which was measured at the

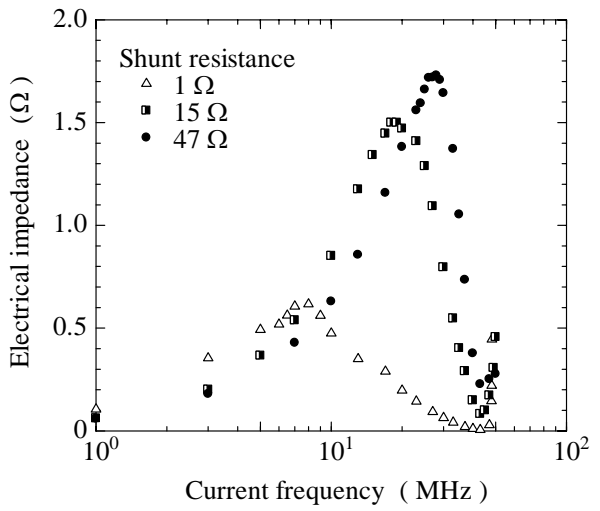

Fig. 12. Resonance characteristic of the circuit

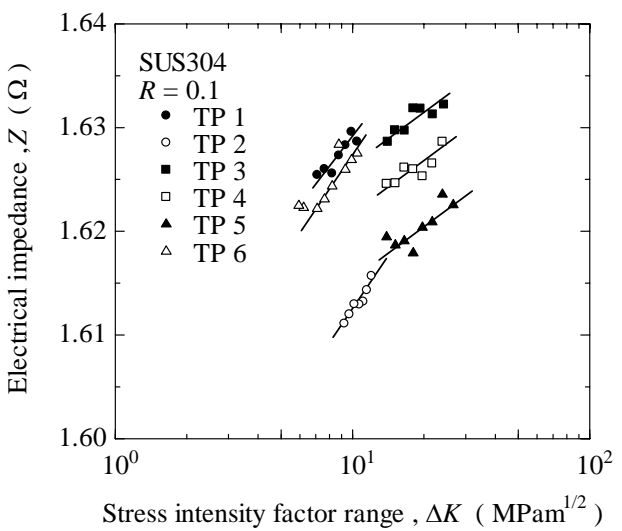

Fig. 13. Relation between the electrical impedance and stress intensity factor range of SUS304 
same time. The unstrained material was solution heat treated and electro-polished.

The relationship between the normalized impedance and stress intensity factor range of SUS304 and SUS316L for both constant stress ratio and constant $K_{\max }$ conditions are shown in Figs. 14 and 15. In SUS304, there was a correlation between the normalized impedance and stress intensity factor range in the near threshold region for both test conditions. In SUS316L, same tendency was seen. In this study, the depth of monotonic plastic zone below the surface was approximately from 200 to $600 \mu \mathrm{m}$, and the depth of cyclic plastic zone was approximately from 20 to $80 \mu \mathrm{m}$. The skin depth of $23 \mathrm{MHz}$ high frequency current was approximately $30 \mu \mathrm{m}$. Therefore, it can be estimated that most of $23 \mathrm{MHz}$ high frequency current passes through within cyclic plastic zone. Consequently, it can be estimated that the electrical impedance of the fatigue fracture surface measured in this experiment reflected the properties of cyclic plastic zone, that is, it had a correlation with not the maximum stress intensity factor but the range of stress intensity factor.

Figures 14 and 15 also show variation of measurement. In SUS304, the measured values were with a range of factor of 2, which was taken in horizontal direction. In SUS316L, the measured values were almost with a range of factor of 3 . Although applied stress estimation is supposed to be possible in both materials, accuracy of applied stress estimation in SUS304 is better than that in SUS316L.

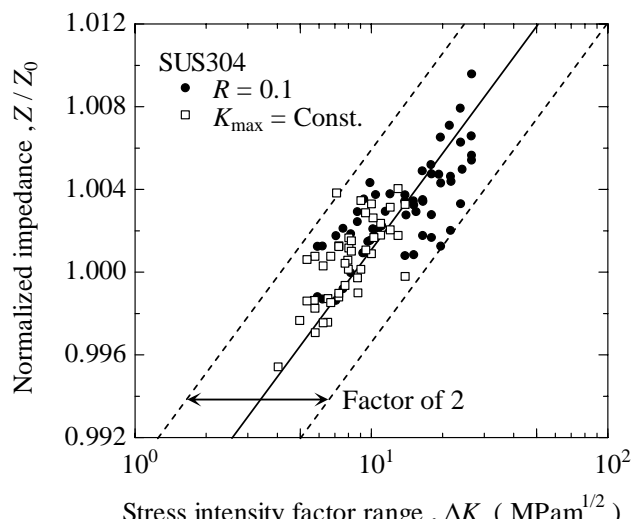

Fig. 14. Relation between the normalized impedance and stress intensity factor range of SUS304

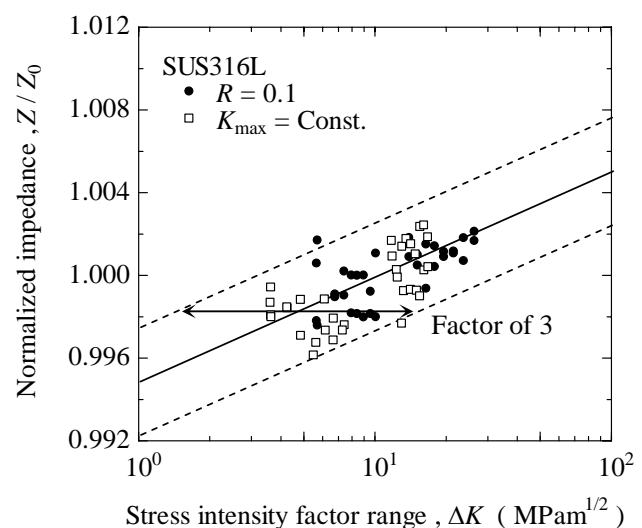

Fig. 15. Relation between the normalized impedance and stress intensity factor range of SUS316L

\subsubsection{Assessment of normalized impedance}

As shown in Figs. 14 and 15, several data points of normalized impedances were less than 1.0. When the basic idea of this method is reminded, it is not expected that the impedance of fracture surface is less than that of unstrained material. Therefore, an examination to understand the reason why this happened was done. The removal of surface roughness was done by electro-polishing after the measurement of electrical impedance of the fracture surface. And then, the impedance was measured again. The results of this examination are shown in Fig. 16. Normalized impedance measured after the removal of surface roughness was higher than that of the original fracture surface. Therefore, it can be considered that the roughness of fracture surface has some effect to reduce the value of electrical impedance.

\section{HARDNESS MEASUREMENT METHOD}

\subsection{Experimental procedure}

Micro Vickers hardness was measured on the fatigue fracture surface. Since fatigue fracture surface has relatively large roughness compared with the size of indentation mark, Vickers indentation mark on fatigue fracture surface shows inappropriate shape to measure the actual Vickers hardness. In this experiment, the hardness of fatigue fracture surface was defined as the area of indentation mark. An example of indentation mark is shown in Fig. 17. The test load was $0.49 \mathrm{~N}$. The area of indentation mark was calculated by using the following equation.

$$
\text { Area }=\frac{d_{1} \times d_{2}}{2}
$$

Where, $d_{1}$ and $d_{2}$ are the lengths of diagonal lines. The depth of indentation mark is supposed to be less than 4 $\mu \mathrm{m}$, and it is less than the depth of plastic deformation layer. Therefore, the test load is supposed to be suitable.

It could be expected that the area is widely scattered due to the roughness of surface. Therefore, statistical treatment was applied. Examples of the results for SUS304 are shown in Fig. 18. The ordinate of the figures is the accumulated probability of normal distribution. The results distributed almost following normal distribution. Therefore, the average value was used to evaluate the stress intensity factor range. In this paper, the average

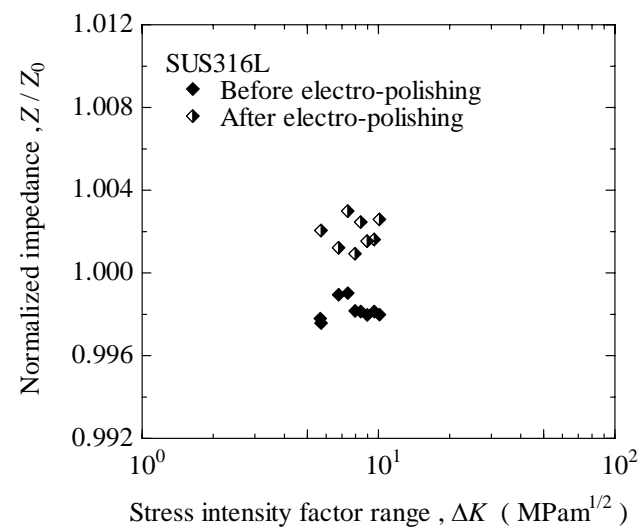

Fig. 16. Comparison of electrical impedance of fatigue fracture surface before and after removal of surface roughness 
value of the areas is called "hardness parameter". In the actual hardness, small hardness number means soft material. However, in this study, small value of hardness parameter indicates hard fracture surface.

\subsection{Results and discussions}

The relationship between hardness parameter and stress intensity factor range of SUS304 under both constant stress ratio and constant $K_{\max }$ conditions is shown in Fig. 19. Figure 20 shows the results of SUS316L. In both materials, fatigue fracture surface had lower hardness parameter than unstrained material surface. The actual hardness of fatigue fracture surface increased with the increase of stress intensity factor range in the region where stress intensity factor range was from 10 to 30 $\mathrm{MPam}^{1 / 2}$. In this region, this method could be applicable for the $\Delta K$ estimation.

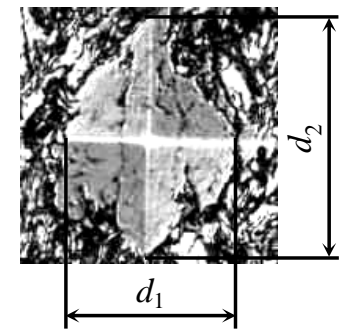

Fig. 17. Example of Vickers indentation

\section{CONCLUSIONS}

Two kinds of non-destructive applied stress estimation methods using fracture surface, which could be applicable in relatively low stress intensity factor range region, were proposed. The results were summarized as follows: (1) Normalized electrical impedance measured on fatigue fracture surface using high frequency current showed a positive correlation with stress intensity factor range.

(2) Hardness of fatigue fracture surface increased with the increase of stress intensity factor range in the region where stress intensity factor range was from 10 to 30 $\mathrm{MPam}^{1 / 2}$

\section{ACKNOWLEDGMENT}

This study was done by the fond of Grand-in-Aid for Scientific Research from Japan society for the promotion of science.

\section{REFERENCES}

1. H. Kitagawa and R. Koterazawa, Fractography, Baifukan(1977).

2. M. Fujihara, Y. Kondo and T. Hattori, JSMS, 40-453(1991), p.712-717.

3. Y. Kondo and H. Kanasaki, Trans JSME, Ser. A, 66-645(1999), p.909-914.

4. National Astronomical Observatory of Japan, Rikanenpyou, Maruzen(2003).
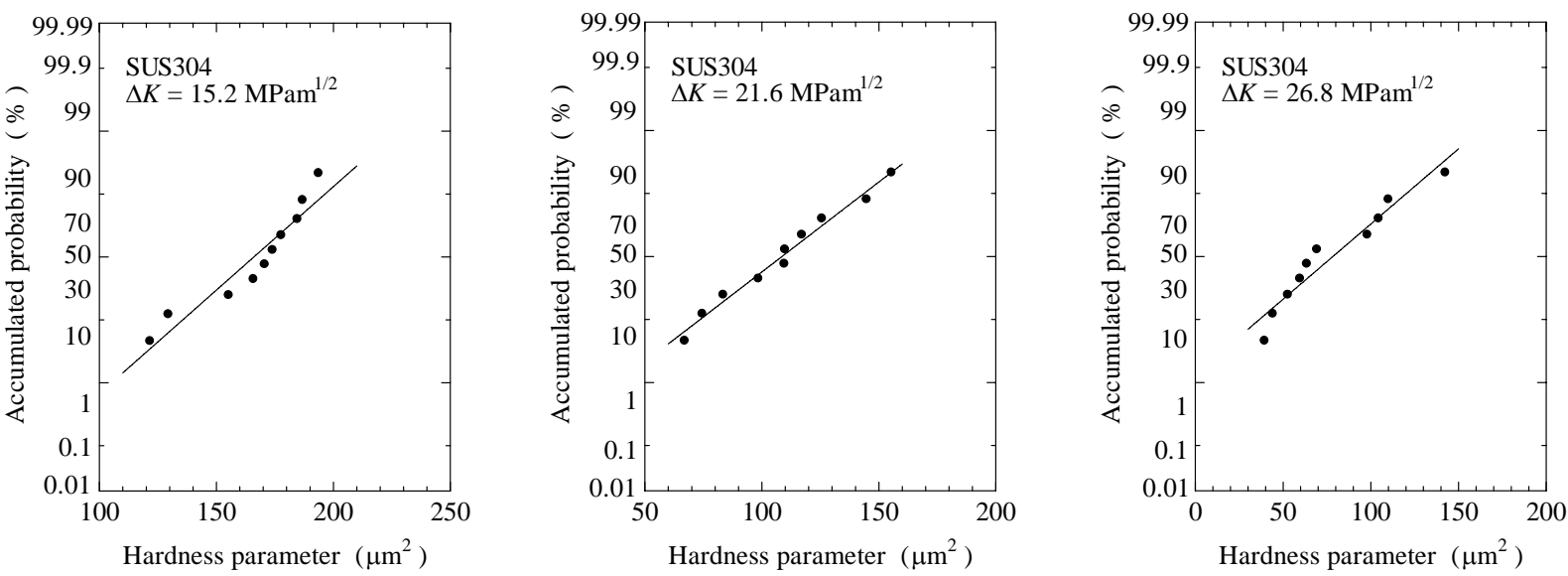

Fig. 18. Results of fracture surface hardness measurement of SUS304

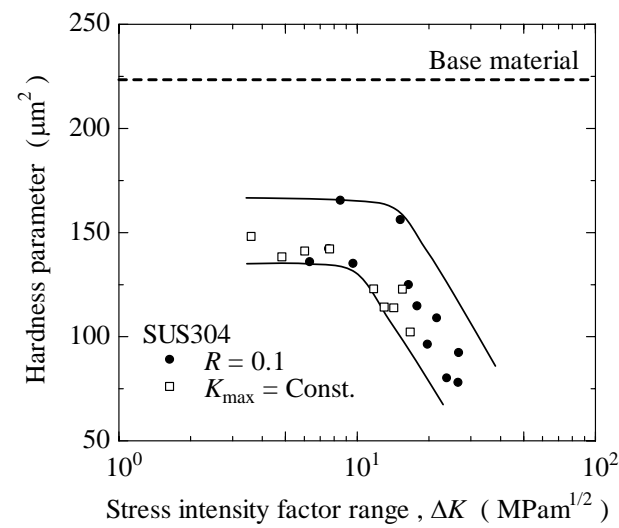

Fig. 19. Relation between hardness parameter and stress intensity factor range of SUS304

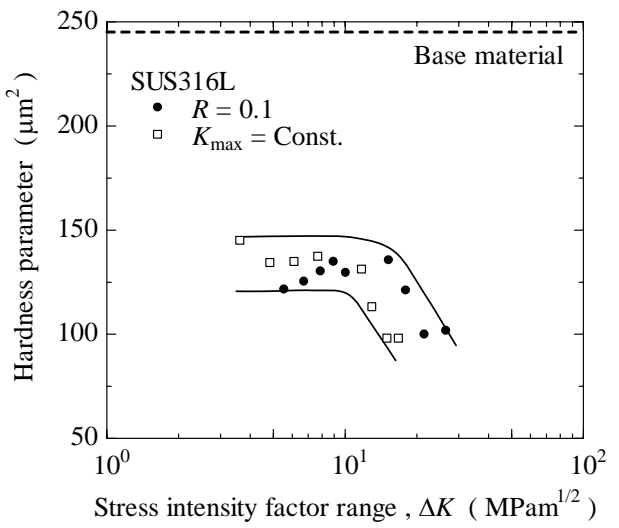

Fig. 20. Relation between hardness parameter and stress intensity factor range of SUS316L 